\title{
Compression of the Cauda Equina due to a Necrobiotic Granuloma of Ligamentum Flavum
}

\author{
JUAN M. BILBAO, WILLIAM HORSEY, CHARLES GONSALVES AND ARA CHALVARDJIAN.
}

SUMMARY: A 56 year old woman developed symptoms of lumbar nerve root compression caused by a granuloma arising in the ligamentum flavum. The histological features of the lesion are discussed and the clinical and radiological findings of the patient are described.

RÉSUMÉ: Une femme de 56 ans a développé des signes de compression lombaire causés par un granulome dans le ligamentum flavum. Les signes histologiques de cette lésion sont décrits et les données cliniques et radiologiques chez cette patiente sont décrites.

From the Departments of Pathology, Neurosurgery and Radiology, St. Michael's Hospital and the University of Toronto.

Reprint requests to Dr. Juan M. Bilbao, Department of Pathology, St. Michael's Hospital, Toronto, Ontario MSB IW8

\section{INTRODUCTION}

Non-traumatic, degenerative, changes of the spinal ligaments are rarely reported as the cause of nerve root compression. This report, we believe, represents the first histological demonstration of cauda equina compression from a necrobiotic granuloma of the ligamentum flavum in a patient with no evidence of disc disease.

\section{CASE REPORT}

The patient, a 56 year old white female, had backache intermittently for many years. In 1970 she had a lateral medullary syndrome and full angiographic examination disclosed an occlusion of the left vertebral artery at the level of C5. She was left with hypalgesia on her right side below the territory of the 5 th cranial nerve. A lumbar puncture was performed, uneventfully, at that time. Three months prior to admission (February 1974) lumbar pain became severe and radiated to the left buttock and back of the thigh to just below the knee. The pain was aggravated by walking and strenuous activity. There was no history of collagen disease or trauma.

On neurological examination (May 1974) there was excellent power of extension of both knees but deficient power of flexion of both knees and of dorsiflexion and plantar flexion at each ankle. The extensor hallucis longus on each side was weak. Ankle and plantar reflexes were unobtainable. The knee jerk was brisker on the right. Sensory changes in the right lower limb were attributable to the lateral medullary infarct. The clinical impression was that of a compressive lesion of the cauda equina.

$X$-rays of the lumbar spine revealed a slight narrowing of the L3-4 and L5-S1 intervertebral spaces, associated with small, anterior, osteophytes at these levels. A myelogram was accomplished by lumbar puncture at the L2-3 level. There was almost complete obstruction to the caudal passage of contrast medium just above the upper border of the L3-4 disc space (Fig. 1). The appearance was compatible with extradural compression, more pronounced dorsally than ventrally and therefore unlikely to be due to disc prolapse. Some contrast material descended slowly below this lesion after the patient had been maintained in the upright position. Subsequently, with the head dependent, the lower extent of the lesion was shown to be opposite the upper border of the 4th lumbar vertebral body.

At operation it was evident, immediately on penetrating the ligamentum flavum, that there was a deposit of abnormal tissue adherent to the dura and compressing it. A wide laminectomy was performed at L3 with minimal removal of the superior margins of the L4 laminas. A plane of cleavage was found and the tissue was noted to extend on both the right and left sides of the dural sac. The disc was identified 


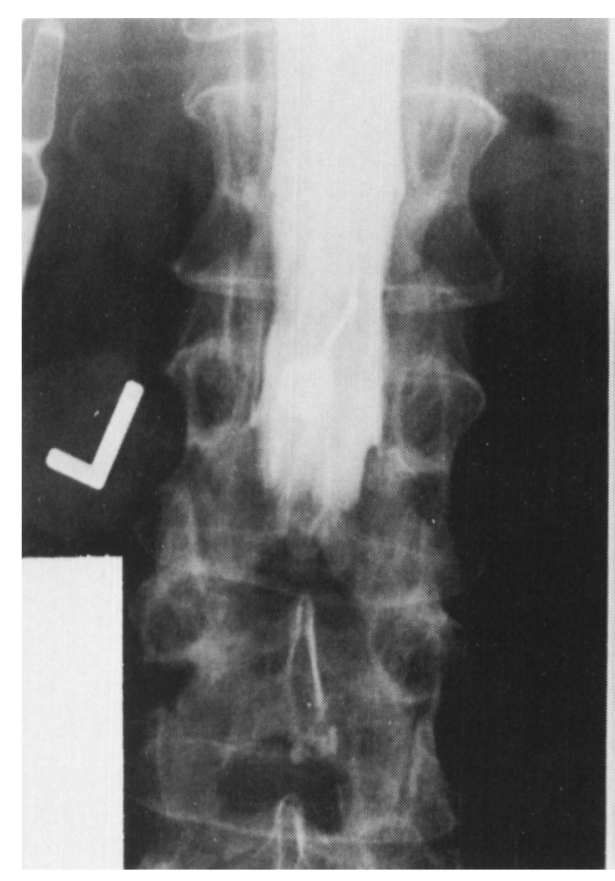

and appeared normal. The patient's post-operative course was uneventful. There was marked improvement in the neurological deficit.

On histological examination there was a central focus of pseudonecrosis (Fig. 2) containing fragments of altered elastica and a peripheral zone with numerous multinucleated giant cells, epithelioid cells, histioc- ytes and occasional mononuclear cells arranged in a palisade-like fashion (Figs. $3 \& 4$ ). Capillary neoformation was conspicuous. Polymorphonuclear leukocyte infiltration, fibrinoid necrosis and vasculitic changes were absent. Ziehl-Nielsen, Gram, Silver methenamine and PAS preparations demonstrated no organisms. No foreign or refractile

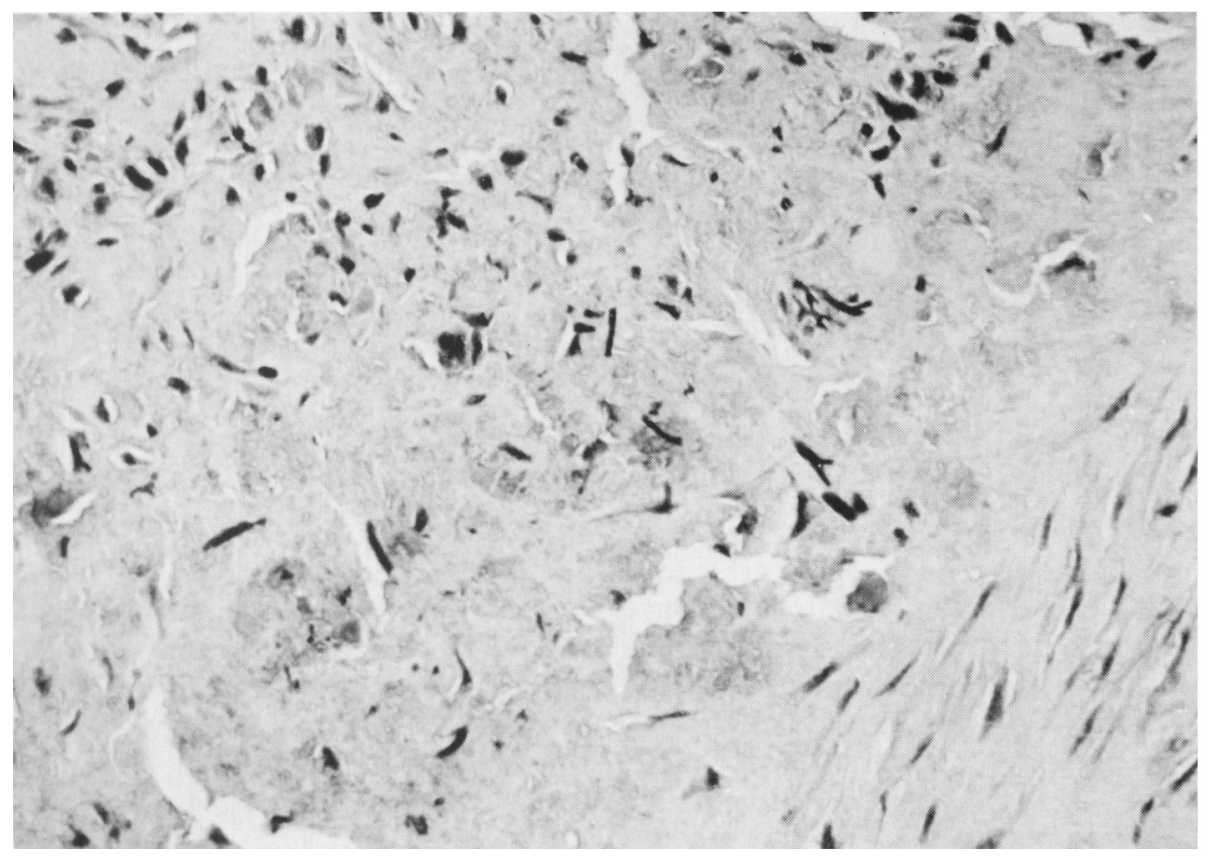

Figure $1-\mathrm{AP}$ and lateral view of the myelogram showing the extradural compression, more pronounced dorsally. material was seen. The remaining elastic tissue exhibited marked fibrosis (Fig. 5) and small foci of calcification. The granuloma extended partially into the epidural space (Fig. 6).

\section{DISCUSSION}

Degenerative changes in the ligamenta flava are not rare

Figure 2-Center of the necrobiotic area showing fragments of elastica and histiocytes. Elastica stain. Original magnification $\times 250$. 
Figure 3-Palisading granulomatous tissue peripheral to a focus of degeneration. Hematoxylin-phloxine-saffron. Original magnification $\times 100$.
(Schmorl and Junghanns, 1971; Herzog, 1949). Fibrosis, hyaline change in blood vessels and focal calcification are frequent in ligaments removed at operation for backache and "sciatica" (Dockerty and Love, 1940). Calcification and ossification of the ligamentum flavum have been reported in association with low back pain (Yanagi, Kato, Yamamura

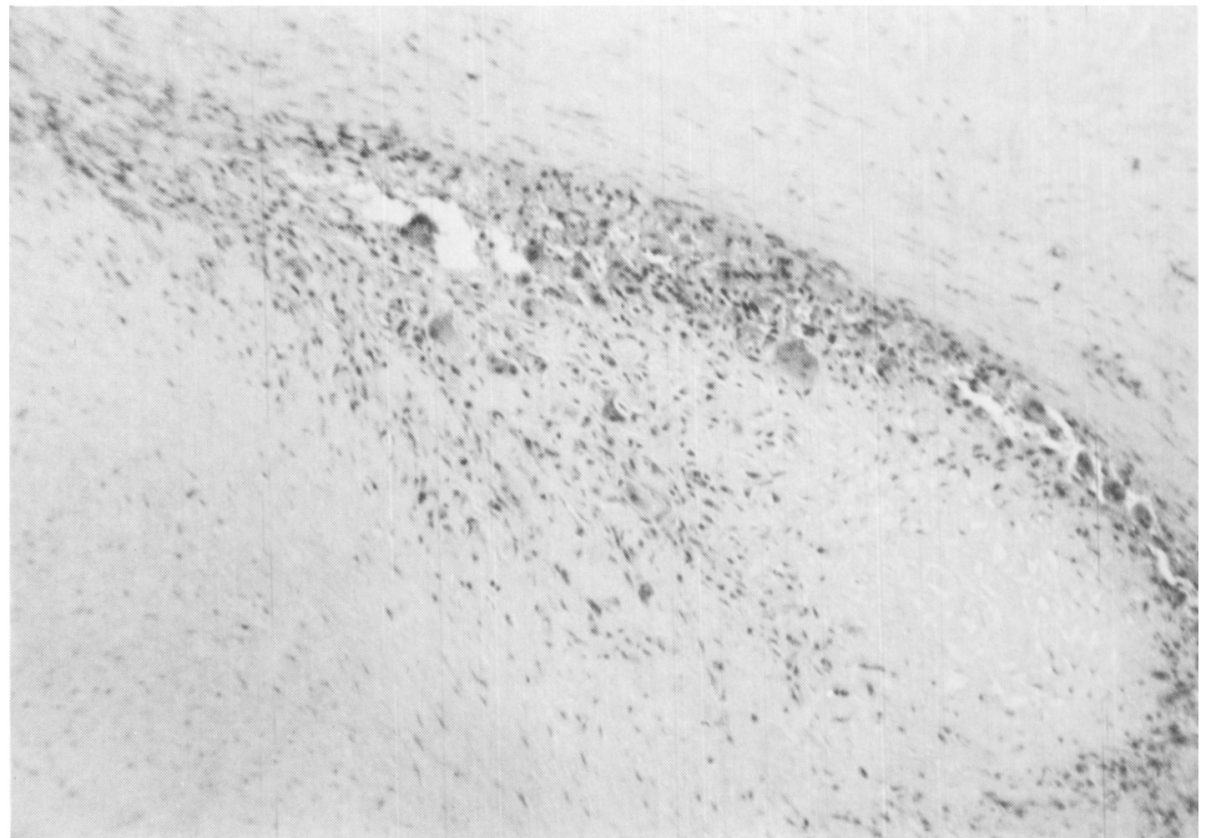

and Sobue, 1972; Voss, 1972), and myelopathy (Soo and Sachdev, 1971; Stoltmann and Blackwood, 1964). Focal necrosis and mucoid degeneration of the yellow ligament was thought to be responsible for sciatic pain in the case reported by Iff (1948).

The cause of the granuloma in the present case remains undetermined.
No similar cases have been found in a careful review of the literature. An infectious agent is ruled out because of the histological appearance, the the negative bacteriological and fungal cultures of the tissue. The palisading arrangement of the granulation tissue, peripheral to a degenerating center, is reminiscent of a absence of stainable organisms and

Figure 4-Detail of palisading granuloma showing multinucleated giant cells, capillary neoformation and epithelioid cells. H.P.S. Original magnification $\mathrm{x} 250$.

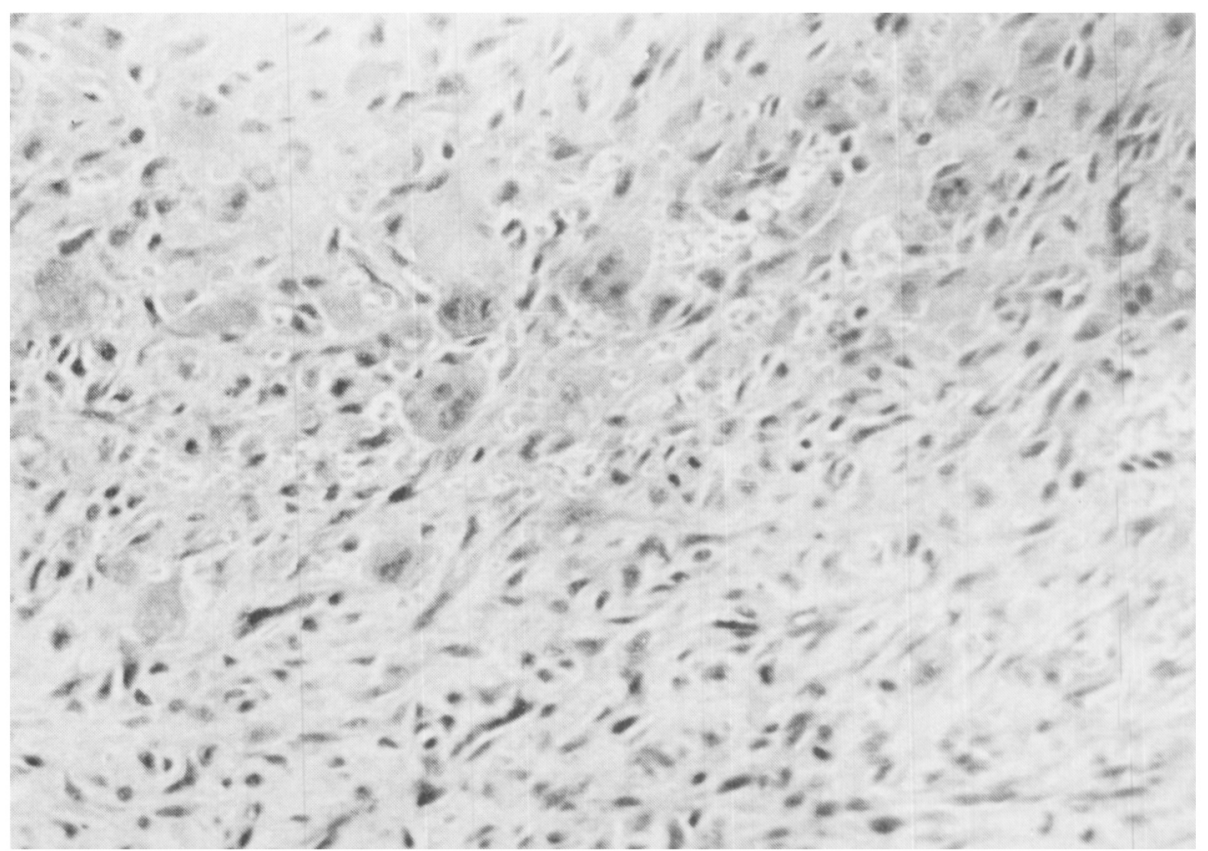




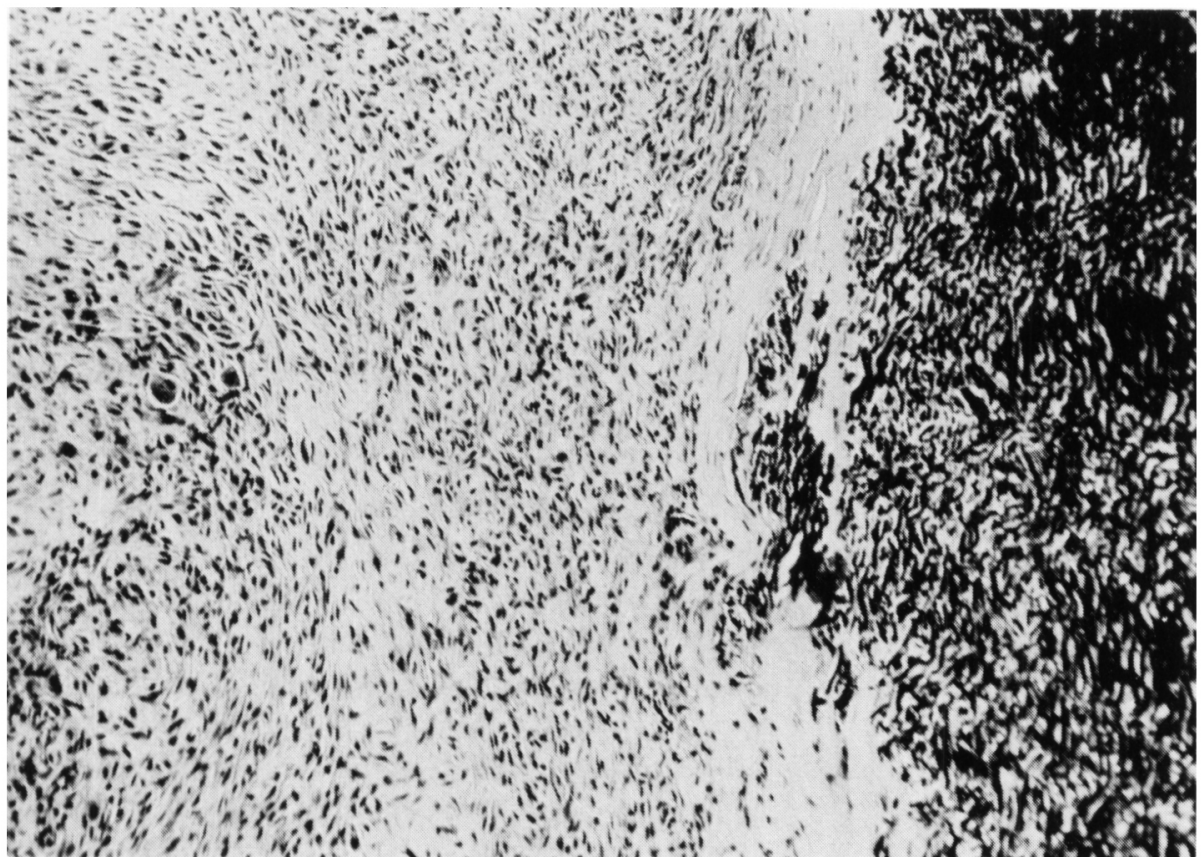

rheumatoid nodule. However, neither rheumatoid arthritis or any other collagen disease was demonstrable in this patient. Trauma to the ligament during the lumbar puncture performed 4 years before the operation remains a possibility, but the lesion appears histologically to be more recent. It is not known at which level the puncture was done.
Damage to the ligament secondary to disc degeneration is excluded by the normal appearance at operation and the absence of X-ray evidence. We suggest that an exuberant reaction of foreign body type took place following primary degeneration of elastic tissue. Whether or not this degeneration has a vascular pathogenesis is not clear.

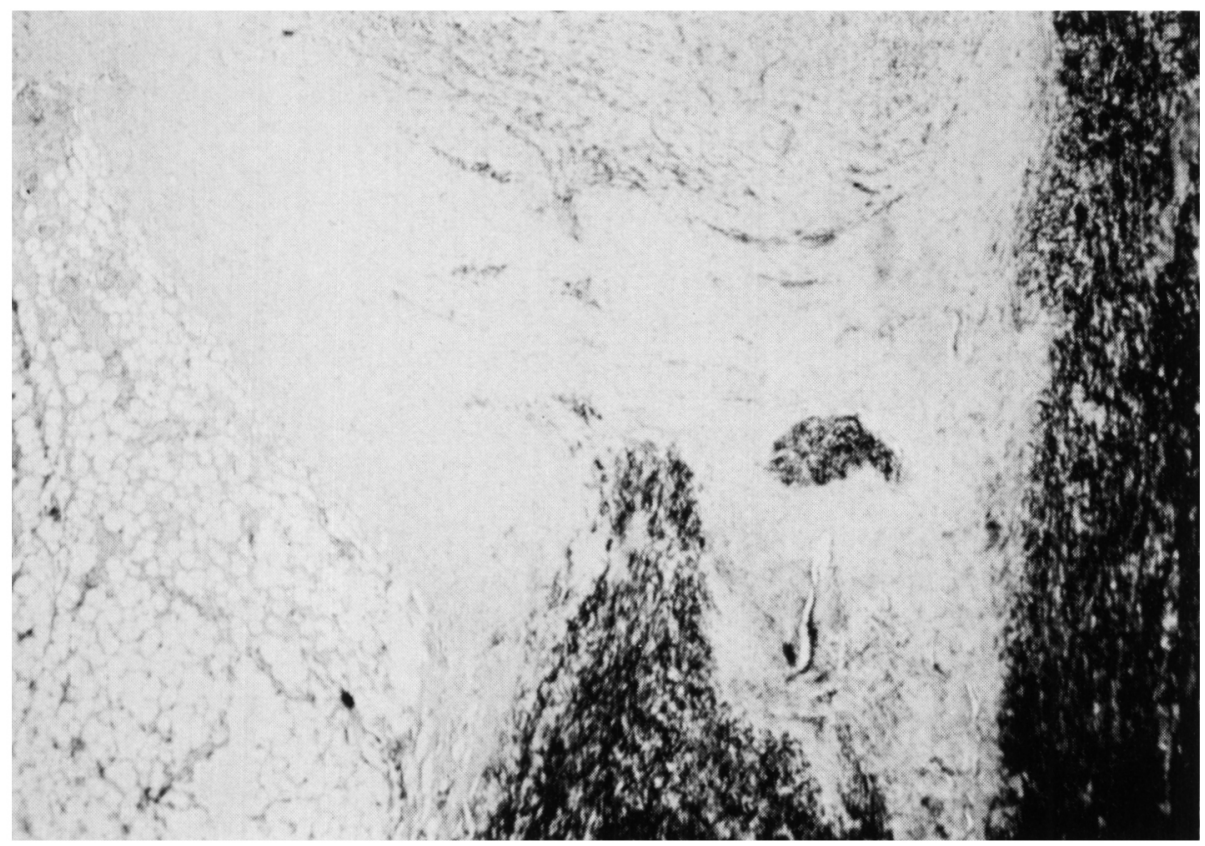

Figure 5-Sharp demarcation between ligament (right) and area of fibrosis and granuloma. Elastica stain. Original magnification $\times 100$.

\section{REFERENCES}

DOCKERTY, M. D., and LOVE, J. G. (1940). Thickening and fibrosis (so called hypertrophy) of the ligamentum flavum: pathological study of 50 cases. Proceedings of the staff meetings of the Mayo Clinic, 15, 161-166.

HERZOG, W. (1949). Zur Morphologie und Pathologie des Ligamentum Flavum. Frankfurter Zeitschrift Fur Pathologie, 61, 250-267.

IFF, W. (1948). Ischias als Folge von Herdformigen Nekrosen und schleimiger Degeneration im Ligamentum Flavum. Praxis, $37,915$.

SCHMORL, G., and JUNGHANNS, $H$. (1971). The human spine in health and disease. Second American Edition translated by BESEMAN, E. F. Grune and Stratton, New York and London.

SOO, Y. S. and SACHDEV, A. S. (1971). Calcification in the posterior longitudinal ligament as a cause of cervical myelopathy. Medical Journal of Australia, 1, 743-745.

STOLTMANN, H. F., and BLACKWOOD, W. (1964). Role of ligamenta flava in pathogenesis of myelopathy in cervical spondylosis. Brain, 87, 45-50.

VOSS, A. C. (1972). Die Verknocherung des Ligamentum Flavum. Fortschritte Auf Dem Gebiete Der Roentgenstrahlen und Der Nuklearmedizin, 117, 226-227.

YANAGI, T., KATO, H., YAMAMURA, Y., and SOBUE, I. (1972). Ossification of spinal ligaments. A clinical and radiological analysis. Clinical Neurology (Tokyo). 12, 571-577.

Figure 6-Granuloma arising within ligamentum flavum and extending into epidural adipose tissue. Elastica stain. Original magnification $\times 25$. 